\title{
Efficient Design Methodology for a Complex DRA-SIW Filter-Antenna Subsystem
}

\author{
Umair Naeem, ${ }^{1,2}$ Amjad Iqbal, ${ }^{3}$ Muhammad Farhan Shafique, ${ }^{4}$ and Stéphane Bila ${ }^{5}$ \\ ${ }^{1}$ Jodrell Bank Centre for Astrophysics, The University of Manchester, Manchester, UK \\ ${ }^{2}$ Department of Electrical Engineering, COMSATS Institute of Information Technology, Islamabad, Pakistan \\ ${ }^{3}$ Department of Electrical Engineering, CECOS University Peshawar, Peshawar, Pakistan \\ ${ }^{4}$ Center for Advanced Studies in Telecommunications, COMSATS Institute of Information Technology, Islamabad, Pakistan \\ ${ }^{5}$ XLIM, UMR 7252, Université de Limoges/CNRS, Limoges, France
}

Correspondence should be addressed to Stéphane Bila; stephane.bila@xlim.fr

Received 11 January 2017; Revised 13 March 2017; Accepted 5 April 2017; Published 30 April 2017

Academic Editor: Yu Jian Cheng

Copyright (C) 2017 Umair Naeem et al. This is an open access article distributed under the Creative Commons Attribution License, which permits unrestricted use, distribution, and reproduction in any medium, provided the original work is properly cited.

This work reports on an efficient design methodology for realizing hybrid filter-antenna subsystems. Designing a filter-antenna subsystem in the case of complex multimode filter is not straightforward. The coupling of the antenna with a multimode filter depends upon several uncorrelated parameters. An efficient design methodology is proposed which can address these complex problems. The work focuses on the characterization of radiating and filtering elements and then proposes a reliable model, which is derived mathematically as well as from rigorous statistical analyses, which can then be used for designing hybrid filter-antenna structures such as a hybrid DRA codesigned with a SIW based multimode filter. A highly compact filter-antenna subsystem has been designed employing the proposed methodology, and the measured results validate the proposed design technique.

\section{Introduction}

High miniaturization trends in wireless communication systems are inspiring researchers to produce compact and costeffective components with easy integration in system-inpackage solutions. Conventionally, in RF front-end modules, the filter and the antenna are realized separately and are connected at 50-ohm reference impedance. This conventional technique limits the degree of freedom in the design of both the filter and the antenna and thus limits the performance of the overall filter-antenna subsystem. A mutual-synthesis technique has been presented in [1] for the design of a filterantenna subsystem, in which the antenna and filters are connected to each other at common optimum impedance rather than the conventional $50 \mathrm{ohms}$. A more generalized methodology was proposed in [2] which was based on the polynomial optimization that can also handle the outof-band constraints. A number of planar and nonplanar filter-antenna designs have been proposed recently. In [3], a nonplanar structure has been proposed in which a horn antenna is covered with a Frequency Selective Surface (FSS) created using Substrate Integrated Waveguide (SIW) cavities to realize a filter-antenna module. In another study, the impedance bandwidth has been improved along with bandwidth and gain enhancement and design miniaturization by having a shared ground plane between the filter and the antenna [4]. A $\Gamma$-shaped filtering antenna has been reported in [5] for GSM, WLANs, LTE, and satellite applications providing flat antenna gain in the pass band and high suppression in the stop band. In [6], a filter-antenna module is integrated through meandered slots.

To reduce the overall size instead of using a classical cascaded basic function approach, a multilayer technology is used in [7] for designing a filter-antenna subsystem. A filtering antenna in [8] is obtained by substituting the resonator and one port of a bandpass filter with fan-shaped patch antenna, where the fan-shaped patch acts as a radiator as well as the second resonator of the filter. A dual band 


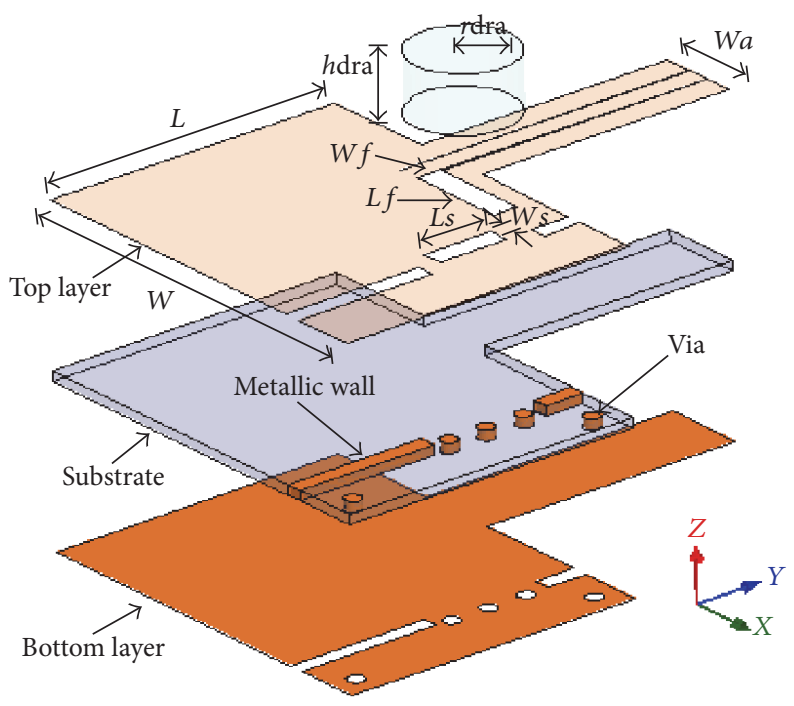

FIGURE 1: The proposed filter-antenna subsystem.

filter-antenna subsystem for Wi-Fi application is achieved by integrating a step impedance resonator filter with a dual band hybrid dielectric resonator antenna (DRA) and monopole antenna [9]. A cavity backed slot antenna was proposed in [10] with improved performance. Various SIW based filters have been proposed in the literature. A multimode cavity filter in SIW technology was proposed in [11] which provides more flexibility in choosing the desired filtering topology.

In this paper, a miniaturized filter-antenna system is proposed in which the DRA acts as the last filter element. The filter is realized through SIW technology. At first, the antenna will be characterized based on the operating mode and excitation system (taking into account the complex multimode filter), from which a reliable model will be extracted, and then a filter-antenna subsystem will be designed exploiting the proposed methodology and finally the measured results will be discussed.

\section{Antenna Characterization}

Dielectric resonator (DR) can radiate and act as an antenna when not bounded by a conductive boundary. The cylindrical DRA has been employed in this work which is integrated with a SIW cavity. The proposed structure is presented in Figure 1. The DR used in this design has dielectric constant, $\varepsilon_{r}$, of 9.8 and dielectric loss tangent, $\tan \delta$, of 0.002 . The radius of DR is $6.35 \mathrm{~mm}$ and height is $9 \mathrm{~mm}$. The SIW filter is fabricated using standard printed circuit technology on Rogers 5880 laminate having dielectric constant of 2.2, loss tangent of 0.0009 , and thickness of $1.575 \mathrm{~mm}$. The length and width of the substrate integrated cavity are $38 \mathrm{~mm} \times 38 \mathrm{~mm}$. The DRA is excited for $\mathrm{HEM}_{11}$ mode through a rectangular slot having length $L s$ of $10 \mathrm{~mm}$ and width $W s$ of $2.2 \mathrm{~mm}$. All the simulations were carried out using a commercially available full-wave finite element method based electromagnetic simulator (ANSYS HFSS).
2.1. Resonant Frequency and Quality Factor. The resonant frequency and Q-factor have been calculated from [12]

$$
\begin{aligned}
& f_{0}=\frac{c \times 6.324}{2 \pi r \sqrt{\varepsilon_{r}+2}}\left(0.27+0.36 x+0.02 x^{2}\right), \\
& Q=x \varepsilon_{r}^{1.2}\left(0.01893+2.925^{-2.08 x(1-0.08 x)}\right),
\end{aligned}
$$

where $x=r / H, r$ is the radius, and $H$ represents the height of DRA.

The resonant frequency and Q-factor of $\mathrm{HEM}_{11}$ mode are calculated theoretically for a radius of $6.35 \mathrm{~mm}$ and height of $9 \mathrm{~mm}$ and were found to be $5.56 \mathrm{GHz}$ and 7.90 , respectively. The resonant frequency and $Q$-factor can be optimized as desired using different combinations of radiusto-height ratio. The quality factor can be enhanced at the cost of larger radius. The radius-to-height ratio of 0.35 has been used in the simulation. The cylindrical DRA is excited with the desired mode of $\mathrm{HEM}_{11}$, and the $E$ and $H$ fields of this mode are plotted in Figures 2(a) and 2(b), respectively.

2.2. Excitation Mechanism. The DRA is excited through a slot as shown in Figure 1 for the desired mode to be installed. The radiation resistance of DRA depends upon the length and width of the slot. Figure 3 establishes the relation between the slot dimensions and radiation resistance. The optimum slot dimensions have been selected from the graph in Figure 3.

2.3. Circuit Model of DRA. The equivalent circuit of the antenna is shown in Figure 4.

In order to verify the proposed model, the input impedance plots of equivalent circuit model and EM model of the DRA are compared in Figure 5. The real and imaginary impedance values show good agreement between circuit and EM model.

Plot of impedance values for different models of antenna are shown in Figures 6(a) and 6(b). Different values of length 
TABLE 1: Different length and width relation with $X_{1}$ and $X_{2}$.

\begin{tabular}{lcccccccc}
\hline $\begin{array}{l}L s / W s \\
(\mathrm{~mm})\end{array}$ & $\begin{array}{c}R_{\text {slot }} \\
(\Omega)\end{array}$ & $\begin{array}{c}L_{\text {slot }} \\
(\mathrm{nH})\end{array}$ & $\begin{array}{c}C_{\text {slot }} \\
(\mathrm{pF})\end{array}$ & $\begin{array}{c}R_{\text {DRA }} \\
(\Omega)\end{array}$ & $\begin{array}{c}L_{\text {DRA }} \\
(\mathrm{nH})\end{array}$ & $\begin{array}{c}C_{\text {DRA }} \\
(\mathrm{pF})\end{array}$ & $X_{1}$ & $X_{2}$ \\
\hline $12 / 1.2$ & 850 & 1 & 0.74 & 280 & 1 & 1.8 & 1.77 & 1.326 \\
$10 / 2.2$ & 850 & 1 & 0.74 & 280 & 1 & 1.8 & 1.595 & 0.968 \\
$9 / 2.7$ & 850 & 1 & 0.74 & 280 & 1 & 1.8 & 1.865 & 0.808 \\
$8 / 1.8$ & 850 & 1 & 0.74 & 280 & 1 & 1.8 & 2.45 & 0.55 \\
\hline
\end{tabular}

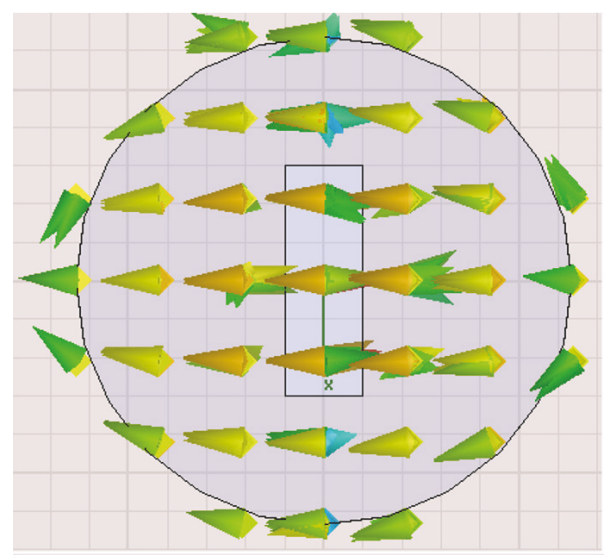

(a)

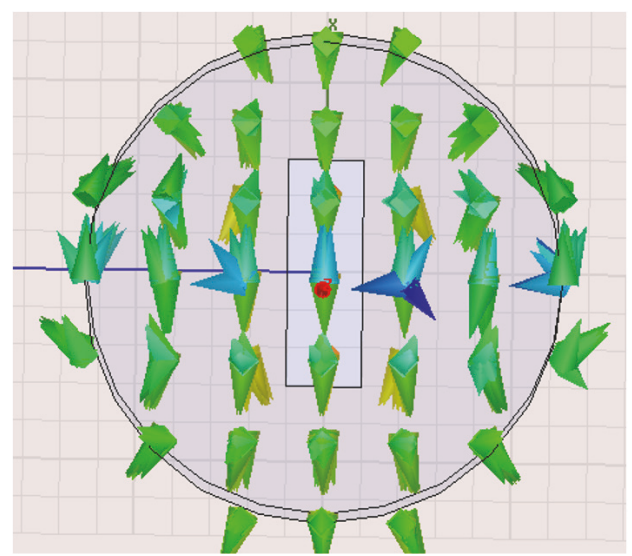

(b)

Figure 2: Top view of DRA (a) $E$-fields and (b) $H$-fields, for $\mathrm{HEM}_{11}$ mode.

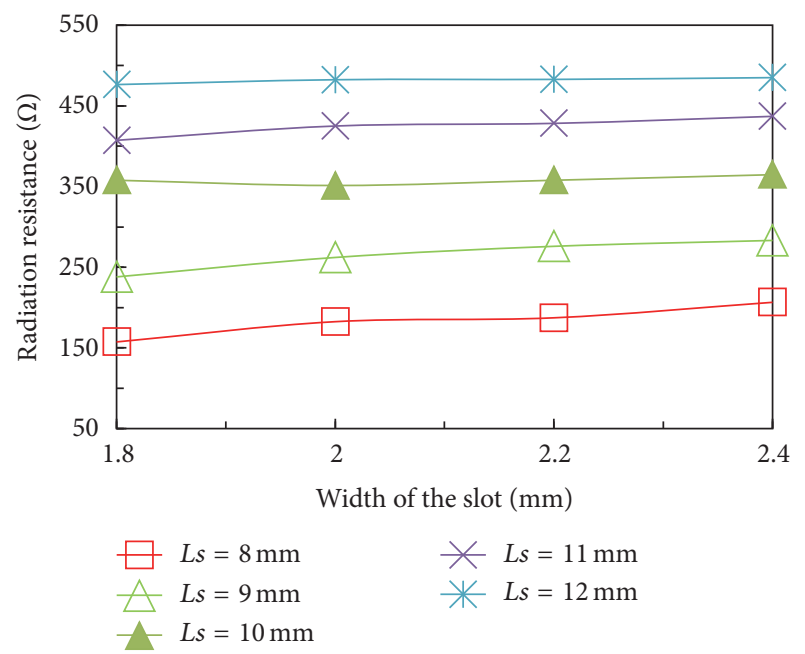

FIGURE 3: Simulated radiation resistance for different lengths and widths of the slot.

and width of the slot (i.e., $X_{1}$ and $X_{2}$ ) are taken and the impedance values are observed.

In order to calculate the length of the coupling slot, a graph is presented in Figure 7 which shows different values of $X_{1}$ and $X_{2}$ as a function of slot length for different slot widths.

The antenna structure is further examined, and the circuit element values (extrapolated from Figure 7) for different combinations of $L s$ and $W s$ are summarized in Table 1.

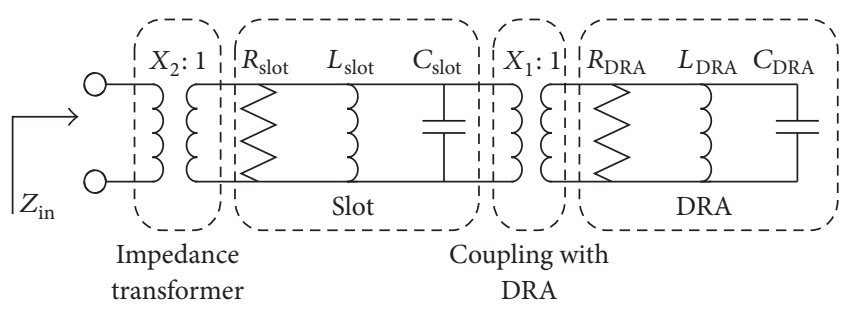

FIGURE 4: Equivalent circuit model of DRA excited by a slot. $R_{\text {slot }}=$ $850, L_{\text {slot }}=1 \mathrm{nH}, C_{\text {slot }}=0.74 \mathrm{pF}, R_{\mathrm{DRA}}=280 \Omega, L_{\mathrm{DRA}}=1 \mathrm{nH}$, $C_{\mathrm{DRA}}=1.177 \mathrm{pF}, X_{1}=0.968$, and $X_{2}=1.595$.

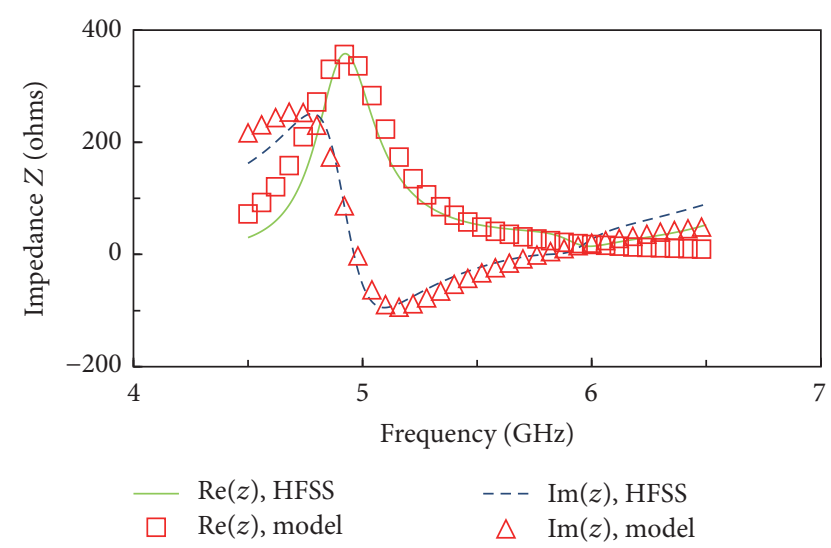

FIGURE 5: Circuit model and simulated input impedance values of DRA. 


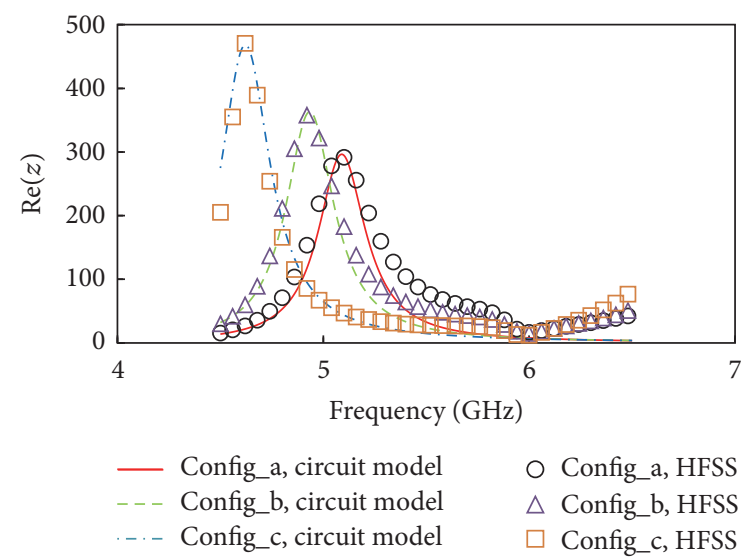

(a)

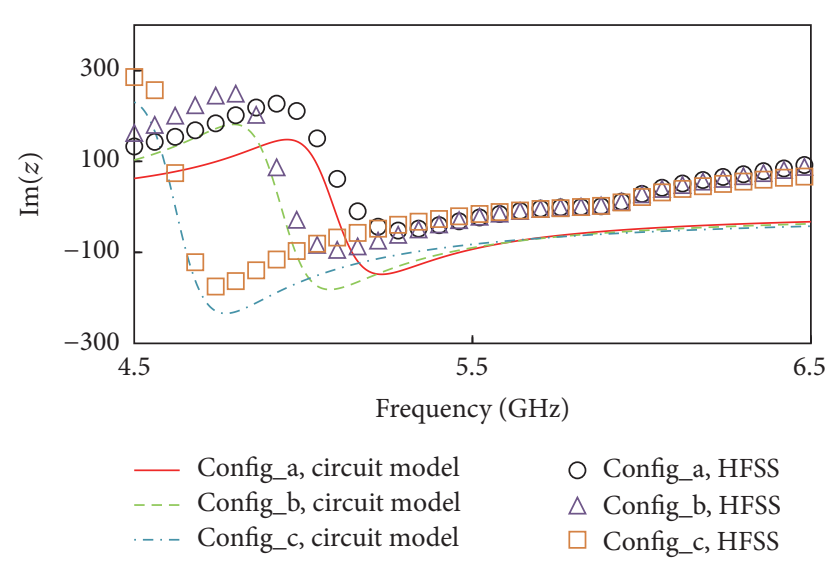

(b)

FIGURE 6: Circuit model and simulated impedance values of DRA for different values of length and width of the slot. (Config_a) $L s=9 \mathrm{~mm}$, $W s=2.7 \mathrm{~mm}$ (aspect ratio 3.3). (Config_b) $L s=10 \mathrm{~mm}, W s=2.2 \mathrm{~mm}$ (aspect ratio 4.54). (Config_c) $L s=12 \mathrm{~mm}, W s=2.2 \mathrm{~mm}($ aspect ratio 5.45).

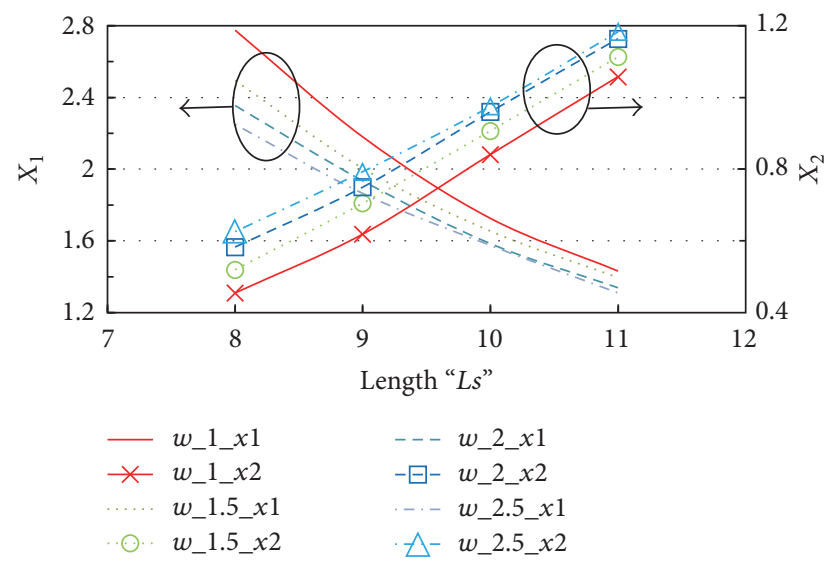

Figure 7: Plot of $X_{1}$ and $X_{2}$ for different values of length with fixed slot widths. Solid lines are for $W s=1$, dotted lines are for $W s=1.5$, dashed lines are for $W s=2$, and solid-dotted lines are for $W s=2.5$.

\section{Filter-Antenna Subsystem}

After characterization of the antenna for the desired frequency and mode, the antenna model is connected with the filter and integrated in the same package.

3.1. Codesigning of Filter with Antenna Model. A dual mode SIW cavity filter is optimized, and a detailed description of the filter is illustrated in Figure 8. The capabilities to achieve different filtering function through the dual mode filters were explored in [11]; a similar filter structure is adopted for the design methodology proposed in this work. The filter is now codesigned with the antenna model. The antenna and the filter have been connected to each other through common reference impedance which is optimized for both the antenna and the filter. This will increase the degree of freedom for the design of both the antenna and the filter. The dependence of the external quality factor $Q_{e}$ and coupling coefficient $k$ is detailed in Figures 9(a) and 9(b), respectively, for different

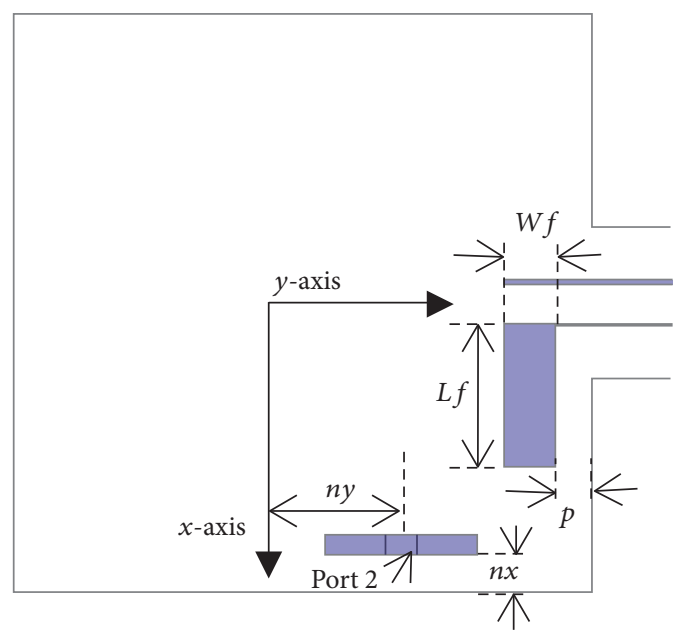

FIGURE 8: The dual mode SIW cavity filter.

design parameters that can be easily optimized through these graphs. The circuit model of the filter is shown in Figure 10. Hence,

$$
\begin{aligned}
& M_{S i}=M_{j L}=\sqrt{\frac{f_{o}}{d f \times Q_{\text {ext }}}}, \\
& M_{12}=\frac{f_{o} \times K_{12}}{d f},
\end{aligned}
$$

where $i, j$ may have the value $=S, N-, 1,2, N+, L$.

The filter designed at $50-\mathrm{ohm}$ impedance at input and output, when connected with the antenna, will only result in optimum match when the antenna is also designed at 50-ohm input impedance which will restrict the antenna performance to this impedance region. Instead of following the conventional technique, the filter has been codesigned with the antenna model extracted in the previous section. The transmission and reflection properties of the filter are illustrated in Figure 11(a). Return loss of the filter-antenna 


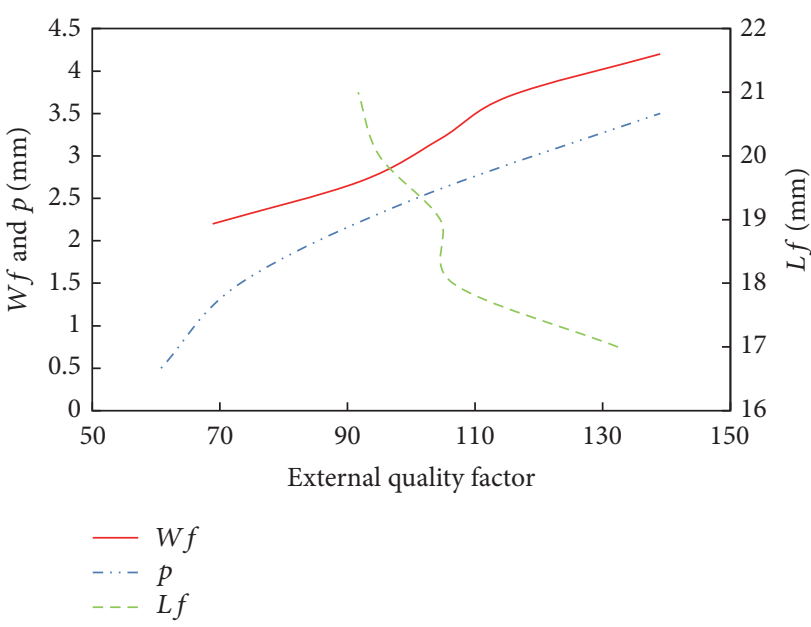

(a)

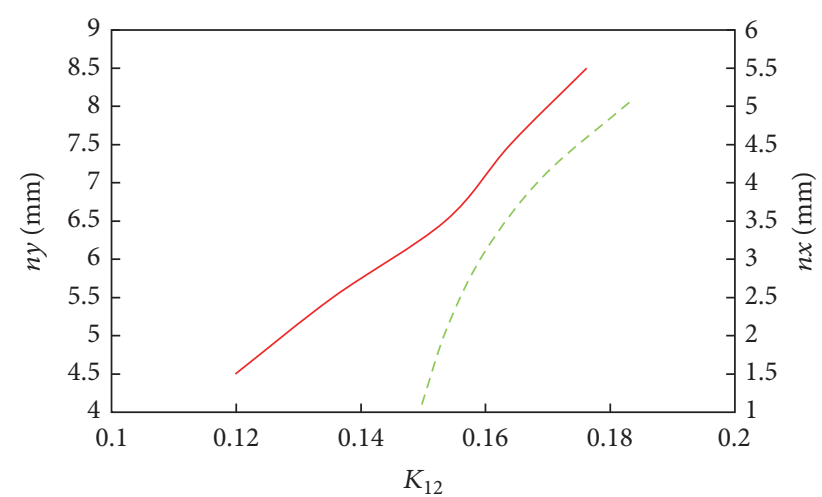

$-n y$

(b)

Figure 9: (a) External quality factor versus $W f$ when $L f=9.5 \mathrm{~mm}$ and $p=2.5 \mathrm{~mm}$, versus $p$ when $W f=3.2 \mathrm{~mm}$ and $L f=9.5 \mathrm{~mm}$, and versus $W f$ when $L f=9.5 \mathrm{~mm}$ and $p=2.5 \mathrm{~mm}$. (b) Coupling coefficient.

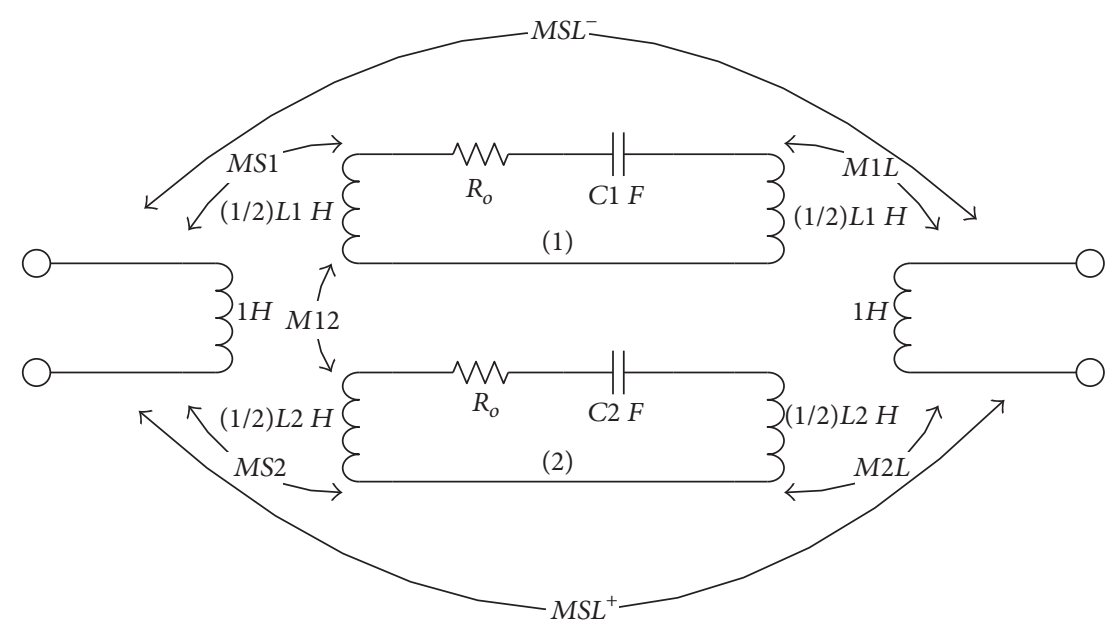

FIGURE 10: Equivalent circuit of the filter.

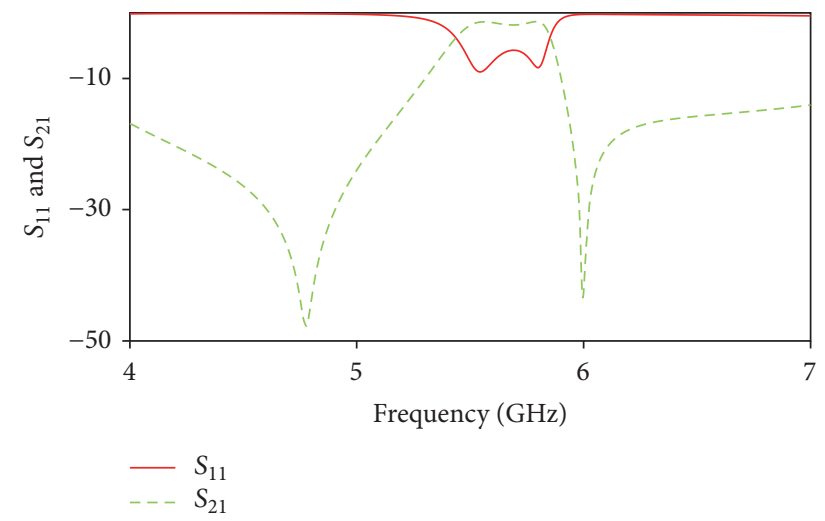

(a)

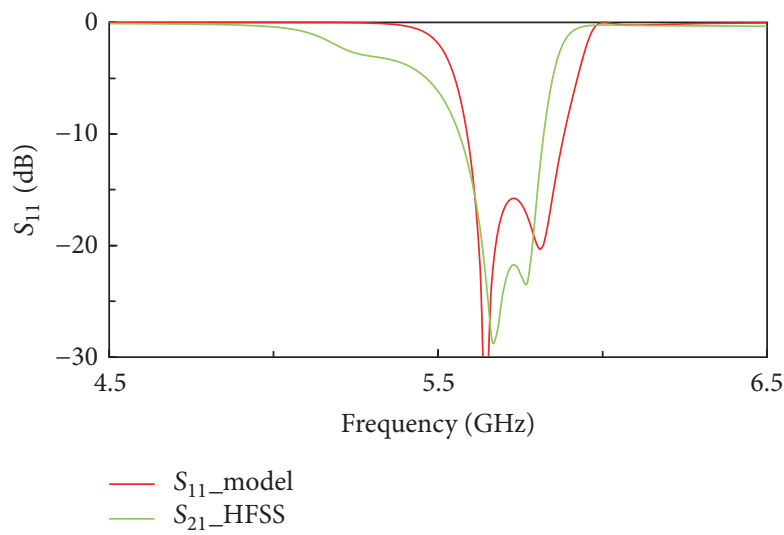

(b)

Figure 11: (a) $S$ parameters of the filter optimized for the subsystem $\left(S_{11}\right.$ in solid red and $S_{21}$ in dashed green). (b) Return loss of the filterantenna subsystem connected at common optimized impedance. 
TABLE 2: Element values for the optimized circuit model.

\begin{tabular}{lccccccr}
\hline $\begin{array}{l}L s / W s \\
(\mathrm{~mm})\end{array}$ & $\begin{array}{c}R_{\text {slot }} \\
(\Omega)\end{array}$ & $\begin{array}{c}L_{\text {slot }} \\
(\mathrm{nH})\end{array}$ & $\begin{array}{c}C_{\text {slot }} \\
(\mathrm{pF})\end{array}$ & $\begin{array}{c}R_{\text {DRA }} \\
(\Omega)\end{array}$ & $\begin{array}{c}L_{\text {DRA }} \\
(\mathrm{nH})\end{array}$ & $\begin{array}{c}C_{\text {DRA }} \\
(\mathrm{pF})\end{array}$ & $X_{1}$ \\
\hline $8 / 1.8$ & 850 & 1 & 0.74 & 280 & 1 & 1.8 & 2.45 \\
\hline
\end{tabular}

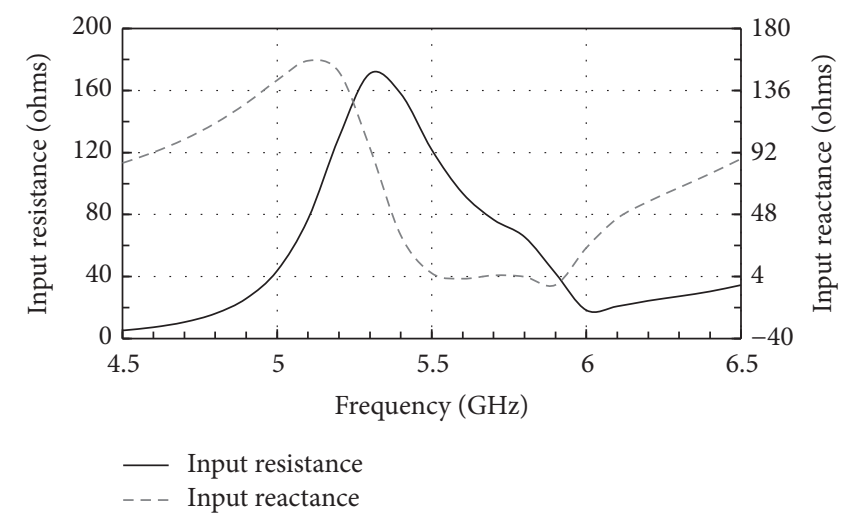

FIGURE 12: The input impedance of the antenna with the filter structure.

subsystem designed at common optimized reference impedance is shown in Figure 11(b). Following are the element values for the optimized circuit model as shown in Table 2. The input impedance of the filter-antenna subsystem for $L s=$ $8 \mathrm{~mm}$ and $W s=1.8 \mathrm{~mm}$ is shown in Figure 12.

The values of $L s$ and $W s$ are interpolated from the graph of Figure 7. $S$ parameters of the filter are shown in Figure 11(b), which are not optimized for 50-ohm output impedance but at optimum common impedance. The coupling matrix of the filter optimized for the subsystem is given by (3), with $f_{o}=5.8 \mathrm{GHz}$ and $d f=190 \mathrm{MHz}$. Here, $N-$ and $N+$ are the nonresonating nodes. Hence,

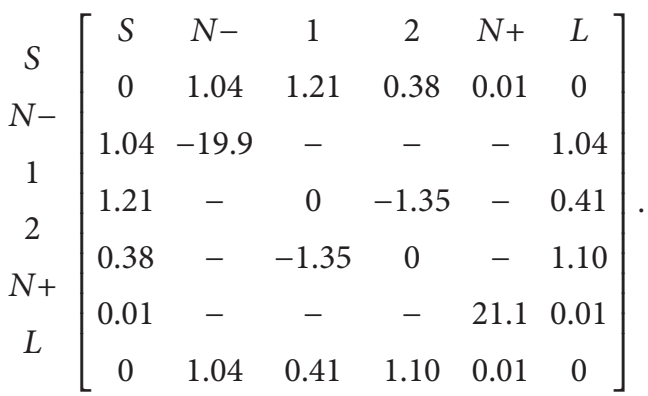

The realized gain of the subsystem designed at $50 \mathrm{ohms}$ is $6.9 \mathrm{dBi}$ whereas the realized gain of the subsystem designed with the proposed methodology is found to be $7.1 \mathrm{dBi}$.

\subsection{Results and Discussion on the Combined Filter-Antenna} Subsystem. The optimized filter-antenna structure has been fabricated as shown in Figure 13(a). The physical dimensions of the optimized structure are given in Table 3.

The simulated and measured results are compared in Figure 13(b). It can be observed that the return loss for both the simulated and the measured cases is better than $20 \mathrm{~dB}$ for a bandwidth of $150 \mathrm{MHz}$ and $10 \mathrm{~dB}$ for a bandwidth of
TABLE 3: Dimensions for the filter-antenna subsystem.

\begin{tabular}{lc}
\hline Parameter & Value $(\mathrm{mm})$ \\
\hline$W$ & 48 \\
$L$ & 38 \\
$W f$ & 3.2 \\
$L f$ & 12.5 \\
$p$ & 2.5 \\
$h d r$ & 9 \\
$r d r$ & 6.35 \\
$W s$ & 1.8 \\
$L s$ & 8 \\
Via (radius) & 1 \\
\hline
\end{tabular}

$250 \mathrm{MHz}$. It can be seen that the filter-antenna subsystem is well matched for the desired frequency of operation.

The copolarization and cross-polarization radiation patterns of the antenna are shown in Figure 14. Figures 15(a) and 15(b) show the realized gain and the radiation efficiency of the proposed filter-antenna subsystem.

The radiation characteristics of the proposed filterantenna subsystem are analyzed in detail. The measured and simulated radiation patterns (normalized) for $E$ fields are compared in Figure 16(a) and for $H$ fields in Figure 16(b). It can be concluded that the measured results of the fabricated prototype validate the proposed simulated design.

A comparison is given in Table 4. The proposed structure presents high selectivity and improved gain performance by using a high efficiency dielectric resonator antenna.

\section{Conclusion}

An efficient design methodology for the design of filterantenna subsystem is proposed. A prototype has been 


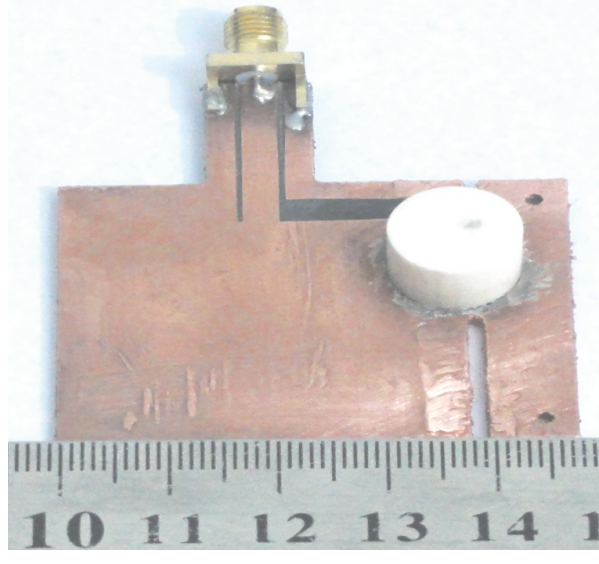

(a)

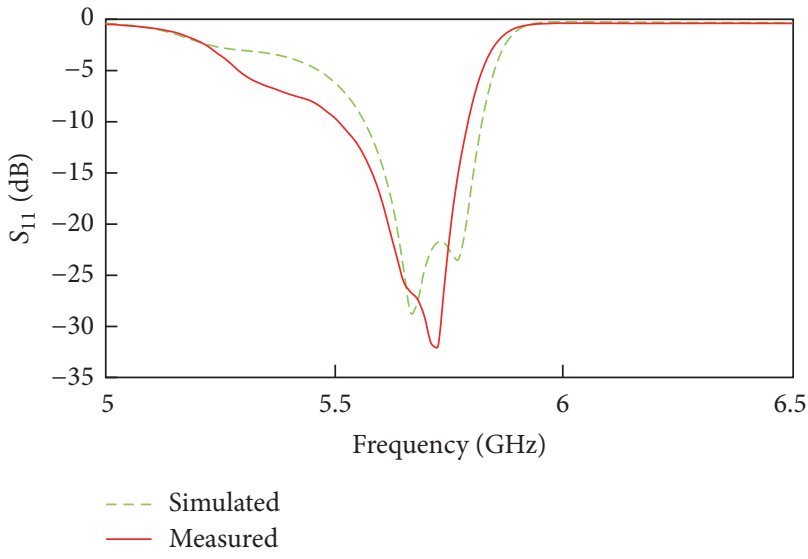

(b)

FIGURE 13: Simulated and measured return loss of the filter-antenna subsystem connected at common impedance.
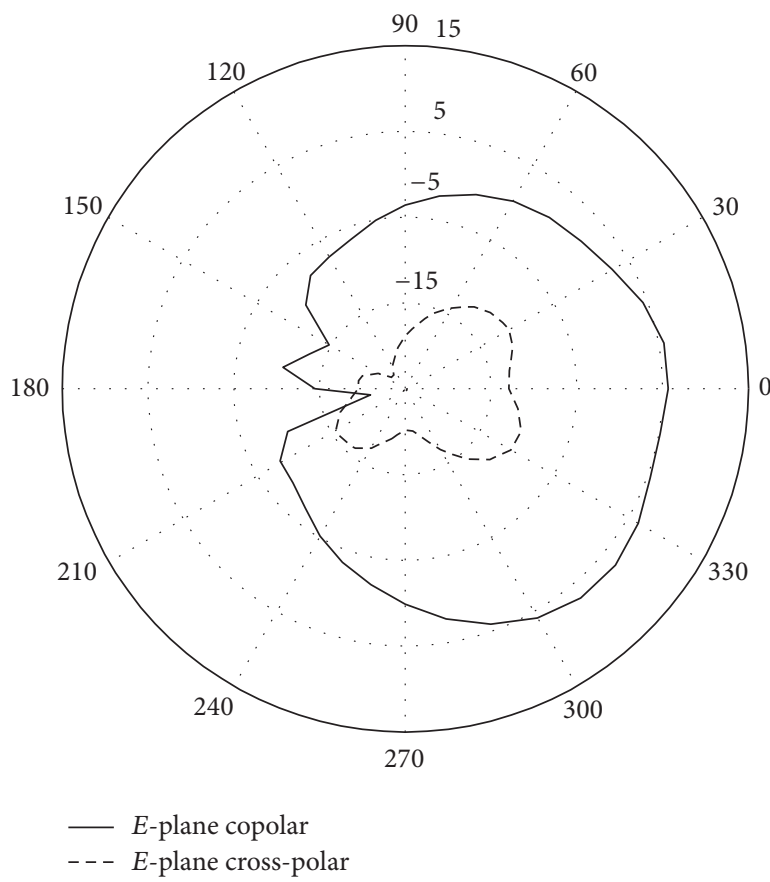

FIGURE 14: E-plane copolar and cross-polar radiation patterns of the antenna.

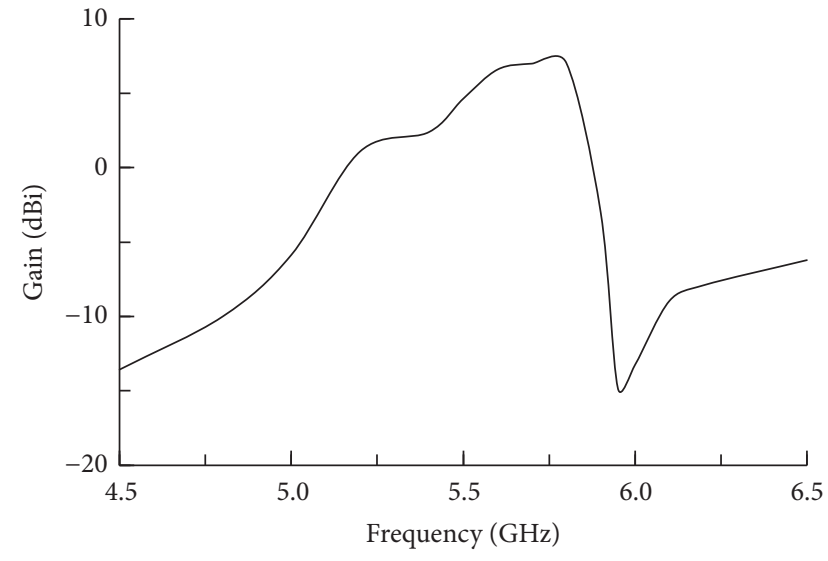

(a)

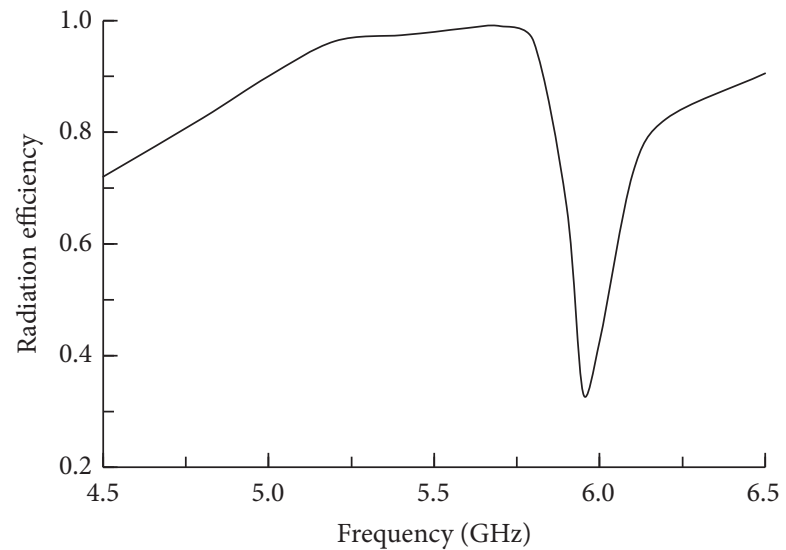

(b)

FIGURE 15: (a) Realized gain and (b) radiation efficiency of the antenna. 


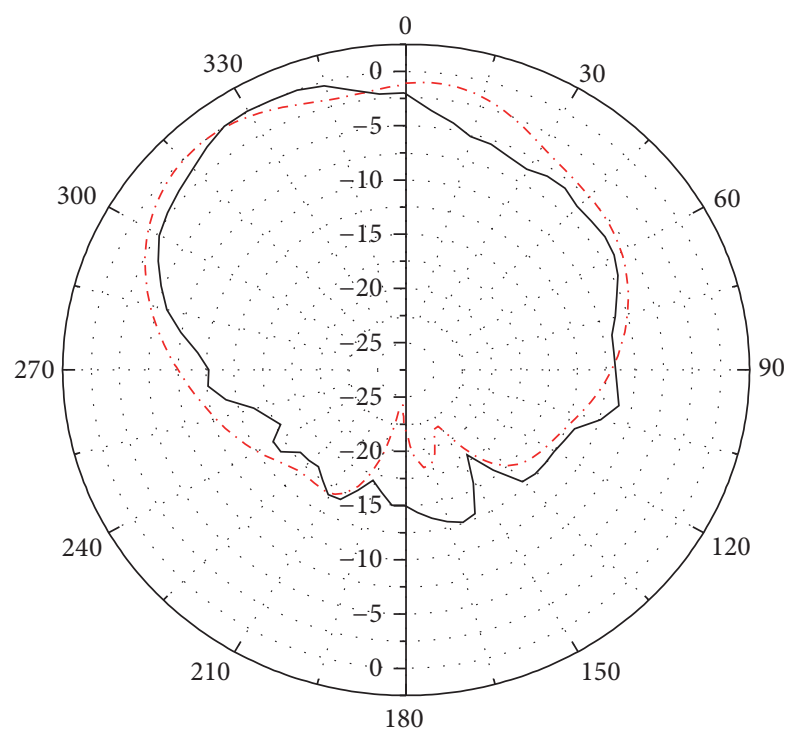

-.- E simulated

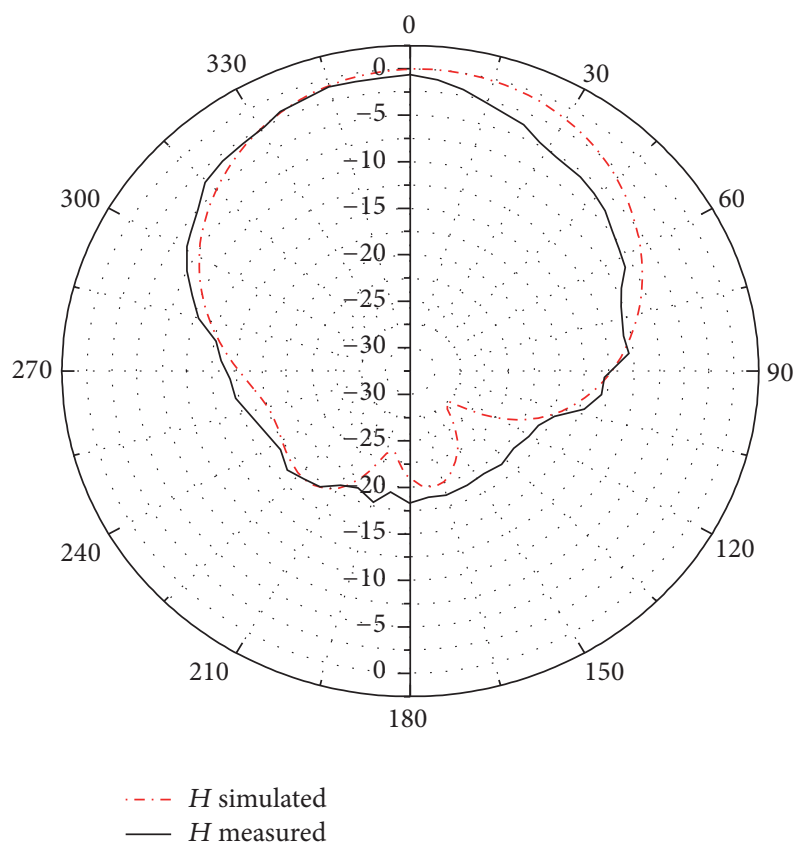

(b)

(a)

FIGURE 16: Simulated and measured radiation patterns.

TABLE 4: Comparison with other filter-antenna systems.

\begin{tabular}{lcccc}
\hline Reference & Gain (dBi) & Bandwidth\% & $\begin{array}{c}\text { Structure } \\
\text { type }\end{array}$ & $\begin{array}{c}\text { Transmission } \\
\text { zeros }\end{array}$ \\
\hline$[4]$ & 4.3 & 4.7 & Planar & 0 \\
{$[5]$} & 2.41 & 16.3 & $\begin{array}{c}\text { Planar } \\
\text { Multilayer } \\
\text { planar }\end{array}$ & 0 \\
{$[6]$} & 4.87 & 5.57 & $\begin{array}{c}\text { Planar } \\
\text { Hybrid } \\
\text { planar }\end{array}$ & 2 \\
This work & 7.1 & 4.2 & & 2 \\
\hline
\end{tabular}

proposed and fabricated employing DRA and SIW based dual mode cavity filter. The measured results are in accordance with the simulated results. The proposed design methodology simplifies the design process and optimizes the impedance between the filter and the antenna, thereby relaxing the constraints on the design of both the filter and the antenna, which consequently results in a subsystem with improved performance.

\section{Conflicts of Interest}

The authors declare that there are no conflicts of interest regarding the publication of this paper.

\section{References}

[1] M. Troubat, S. Bila, M. Thévenot et al., "Mutual synthesis of combined microwave circuits applied to the design of a filterantenna subsystem," IEEE Transactions on Microwave Theory and Techniques, vol. 55, no. 6, pp. 1182-1189, 2007.
[2] U. Naeem, S. Bila, S. Verdeyme et al., "A simplified methodology for matched filter design with constraints-filter-antenna subsystem for space application," in Proceedings of the 2010 IEEE MTT-S International Microwave Symposium (MTT '10), pp. 1664-1667, Anaheim, Calif, USA, May 2010.

[3] G. Q. Luo, W. Hong, H. J. Tang et al., "Filtenna consisting of horn antenna and substrate integrated waveguide cavity FSS," IEEE Transactions on Antennas and Propagation, vol. 55, no. 1, pp. 9298, 2007.

[4] J. Zuo, X. Chen, G. Han, L. Li, and W. Zhang, "An integrated approach to RF antenna-filter co-design," IEEE Antennas and Wireless Propagation Letters, vol. 8, pp. 141-144, 2009.

[5] W.-J. Wu, Y.-Z. Yin, S.-L. Zuo, Z.-Y. Zhang, and J.-J. Xie, "A new compact filter-antenna for modern wireless communication systems," IEEE Antennas and Wireless Propagation Letters, vol. 10, pp. 1131-1134, 2011.

[6] O. A. Nova, J. C. Bohórquez, N. M. Peña, G. E. Bridges, L. Shafai, and C. Shafai, "Filter-antenna module using substrate integrated waveguide cavities," IEEE Antennas and Wireless Propagation Letters, vol. 10, pp. 59-62, 2011.

[7] T. Le Nadan, J. P. Coupez, S. Toutain, and C. Person, "Integration of an antenna/filter device, using a multi-layer, multitechnology process," in Proceedings of the 28th European Microwave Conference (EuMC '98), pp. 672-677, Amsterdam, Netherlands, October 1998.

[8] X. Chen, F. Zhao, L. Yan, and W. Zhang, "A compact filtering antenna with flat gain response within the passband," IEEE Antennas and Wireless Propagation Letters, vol. 12, pp. 857-860, 2013.

[9] U. Naeem, S. Bila, S. Verdeyme, M. Thévenot, and T. Monédière, "A compact dual band filter-antenna subsystem for $802.11 \mathrm{Wi}-\mathrm{Fi}$ applications," in Proceedings of the European Wireless Technology Conference, pp. 181-184, 2010. 
[10] G. Q. Luo, Z. F. Hu, L. X. Dong, and L. L. Sun, "Planar slot antenna backed by substrate integrated waveguide cavity," IEEE Antennas and Wireless Propagation Letters, vol. 7, pp. 236-239, 2008.

[11] U. Naeem and S. Bila, "Compact SIW based multimode filters for future generation wireless front-ends," in 45th European Microwave Conference (EuMC '15), pp. 967-970, Paris, France, September 2015.

[12] K. M. Luk and K. W. Leung, Dielectric Resonator Antennas, Hong Kong Research Studies Ltd, UK, 2003. 


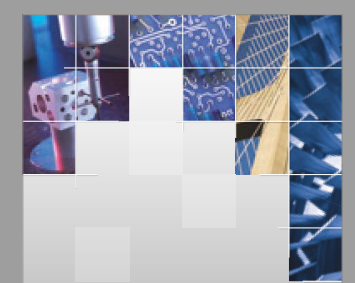

\section{Enfincering}
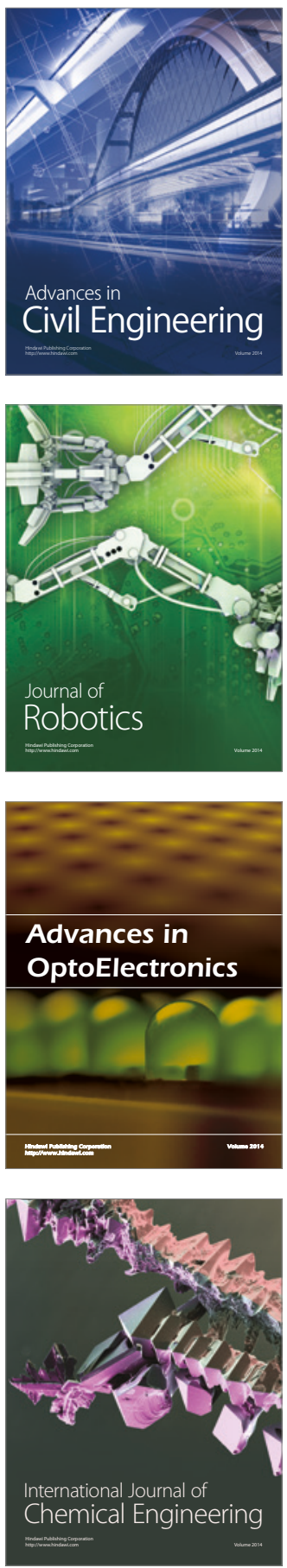

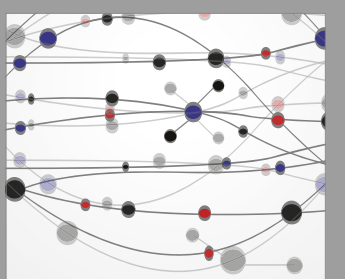

The Scientific World Journal

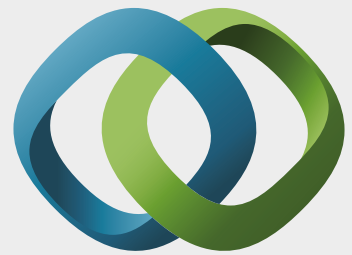

\section{Hindawi}

Submit your manuscripts at

https://www.hindawi.com
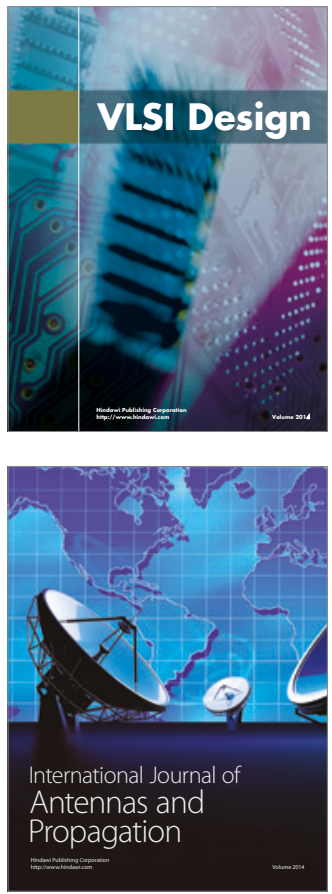

\section{Rotating}

Machinery
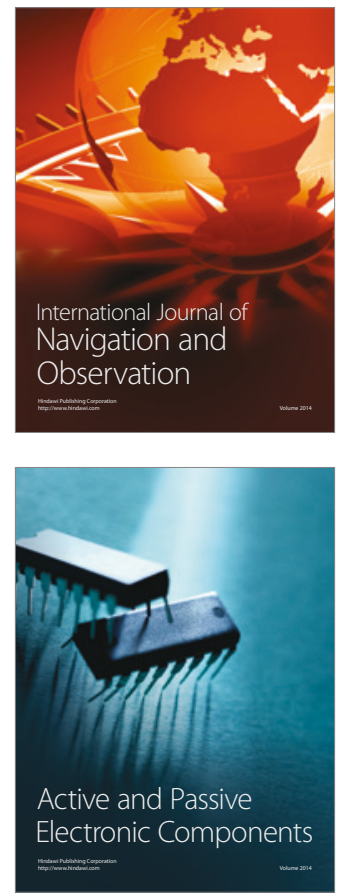
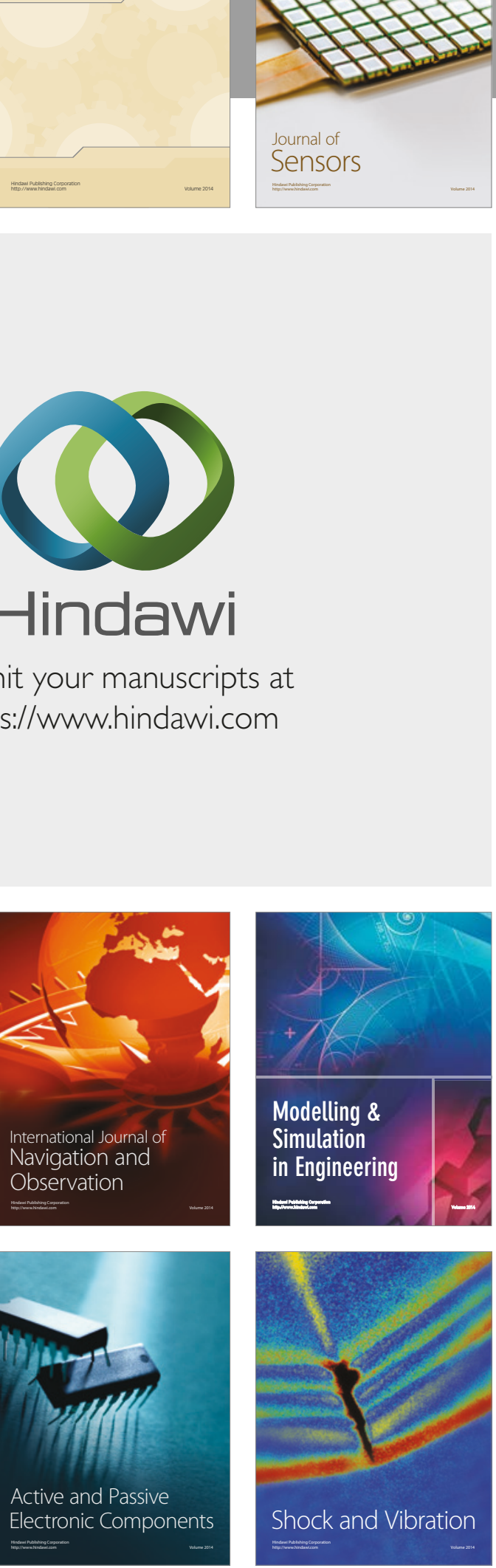
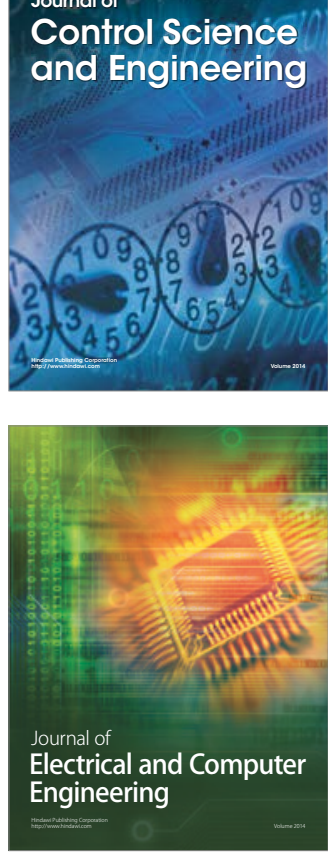

Distributed

Journal of

Control Science

and Engineering
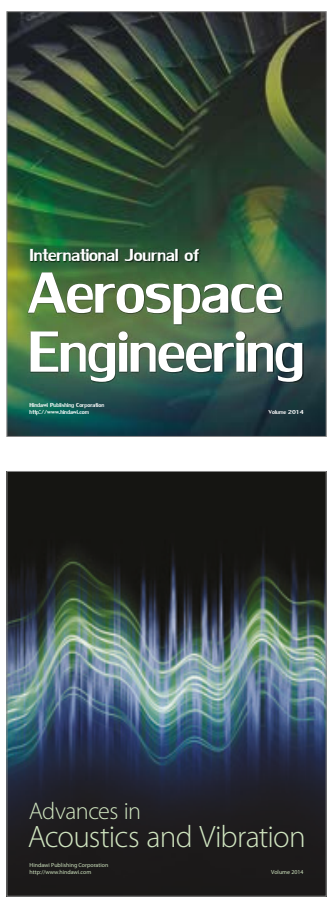

Sensor Networks 